\title{
Microalgae Chlorella Vulgaris Harvesting Via Co-Pelletization with Filamentous Fungus
}

\author{
Ghaidaa Alrubaie $^{1 *}$
}

Rana H. H. Al-Shammari ${ }^{2}$

\author{
Received 8/10/2017 \\ Accepted 29/1/2018
}

This work is licensed under a Creative Commons Attribution 4.0 International License.

\begin{abstract}
:
The objective of this study was to progress another method for coagulation/flocculation of the microalga Chlorella vulgaris via pellet-forming of the fungal species Aspergillus niger which was isolated from municipal wastewater mud and the facultative heterotrophic microalga C.vulgaris was used. The main factors studies were spore inoculums, organic carbon concentration in medium as well as $\mathrm{pH}$ variation which had considerably positive effects on microalgae/fungi co-pelletization formation. The process parameters are an inoculum $1 \times 10^{4}$ spores/ML, $15 \mathrm{~g} / 1$ sucrose as carbon source and $\mathrm{pH}$ ranged from $5-7.0$ were found optimal for efficient microalgae/fungi co-pelletization formation. For autotrophic growth, when $\mathrm{pH}$ of culture broth was adjusted to 5.0 -7.0 with organic carbon addition (15 g/L sucrose), almost complete harvesting efficiency of the microalga was achieved. Furthermore, it was observed that diameter and the concentration of microalgae/fungi pellets were pretentious by the shaker rotation. The new harvesting technology established in this study will decrease the microalga harvesting cost and will be possible to adapt this technique to all microalgal species as an alternative to other old-style harvesting approaches.
\end{abstract}

Keywords: bio flocculation, autotrophic, heterotrophic microalgae, filamentous fungi.

\section{Introduction:}

Microalgae are photosynthetic organisms that can grow rapidly and live in hard conditions because of their simple cellular structure and short life cycle (1, 2). The production of biodiesel from microalgae is not economically feasible because of the very high cost, mainly water pumping, mixing, harvesting the microalga biomass and maintenance require very high-energy inputs $(3,4)$.

Harvesting of algae from water or other liquids culture media is currently a difficult process.Algal cultivation can account for up to $50 \%$ of the total cost of biomass production $(5,6)$ due to the physical properties and nature of algae such as a low density, and the small size and tendency to grow as single cells, they are challenging to harvest (7).

Several methods were used to harvest the microalgae and provide the high value of biomass such as flotation, centrifugation sedimentation, filtration, ultrasonic combination and flocculation can also added to these techniques $(7,8)$. Bioflocculation is a natural flocculation process hastened with biomolecules from microbial cells(9).

${ }^{1,2}$ College of Science, AL- Mustansiriyah University, Baghdad, Iraq.

*Corresponding author: spgh@uomustansiriyah.edu.iq
In recent years, increased attention was focused on cultivation of microalgae with fungi (Cocultivation) for several reasons, the most important of which is the high efficiency of bio-flocculation of microalgal cells for added chemicals and low energy inputs $(10,11,12,13)$. Different microalgae and fungal strains can be applied for this transformative technique. This design was applied to in all areas like in the microbial oil production, wastewater treatment to remove nutrients and heavy metals (11). Aims of the study: Isolation of aquatic filamentous fungi from the municipal wastewater mud in Baghdad City, Evaluating the efficiency of filamentous fungi for the formation of bioflocculation under different growth conditions; autotrophic, heterotrophic and mixotrophic studying the main factors that affect co-culture of microalgae / fungal pellets formation.

\section{Materials and Methods: Experimental project}

The experiments were carried out in three steps. In the first step, filamentous fungal strains were isolated from municipal wastewater. The following isolated fungi: Aspergillus flavous, A. niger, Penicillium sp., Alternaria sp. . The spores of 
applicant fungal strains $\left(1 \times 10^{4}\right.$ spore $/ \mathrm{ml}$ as standard spore suspension) were cultured on glucose peptone broth (GPB) for 5 days and pellets-forming fungal strains were partitioned and identified based on their morphological analyses (14). In the second stage, the isolated promising fungal strain Aspergillus niger was studied for its pellet-forming capability under several culture conditions including different initial inoculate of $A$. niger (approximately $1 \times 10^{6}$ spores $/ \mathrm{ml}$ ), $\mathrm{pH}$ variation (ranged from 5 to 7.0 ), and different sucrose concentrations $(5,10,15,20$, and $25 \mathrm{~g} / \mathrm{l})$ in the medium when cultivated heterotrophically. In the third step, bioflocculation of chlorella vulgaris by pellitization of filamentous fungus A. niger under heterotrophic condition was examined and optimized limitations for efficient fungus assisted algae pelletization were determined. All experiments were carried out in triplicates.

\section{Isolation and description of filamentous fungal strains}

Samples were collected from local municipal wastewater mud from Al-Jaish Channel/ Baghdad city. The following isolated fungi: Aspergillus flavous, A. niger , Penicillium sp., Alternaria sp. were grown in a potato dextrose medium (PDA) in Petri dishs at $25{ }^{\circ} \mathrm{C}$ and the spores were collected from the dish using sterile water and stored at $4{ }^{\circ} \mathrm{C}$ until use (15) .

The isolated fungal strains were tested for pellets forming ability by cultivating spores of candidate strains on typical PGB medium (6 g/l glucose and $4 \mathrm{~g} / \mathrm{l}$ peptone) and those which could form pellets were further identified based on mycelia morphological analysis and extracellular compound- secretion ability when grown on the PDA agar plates. Subsequently, the candidate samples was stained by lacto phenol blue and examined using light microscope then identified according to (16).

\section{Algal strain and growth conditions}

C. vulgaris was isolated from Political Sciences pond in University of Baghdad using streak platingmethod (17) the strain of $C$. vulgaris was used as a model for growth autotrophic growth, heterogeneous and mixotrophic growth in this study.

C.vulgaris grew under the autotrophic condition using Chu-10 culture medium while under heterotrophic condition $15 \mathrm{~g} / \mathrm{l}$ glucose was added to Chu-10 media culture (18). The enriched seed cultures were inoculated by $10 \%(\mathrm{~V}$ inoculation/V medium) on $500 \mathrm{ml}$ liquid medium in $1 \mathrm{~L}$ flasks placed on a horizontal shaker (150 rpm). Culture was kept at a (batch culture) incubated in $25 \pm 2 \mathrm{C}^{\circ}$ with $200 \mu \mathrm{E} / \mathrm{m}^{2} / \mathrm{sec}$ for continuous illumination for autotrophic growth, for heterotrophic growth, cultures were placed under in dark state. For filamentous fungi and algal co-culture, the different initial inocula (approximate from $1 \times 10^{2}$ to $1 \times 10^{6}$ spores $/ \mathrm{ml}$ ) of fungal spores and the glucose were added to the culture broth with different concentrations, and $\mathrm{pH}$ of culture broth was adjusted accordingly by addition of $1 \mathrm{M}$ sulfuric acid solution to culture broth.

\section{Spore inoculum}

Fungal spore suspension was obtained by rinsing the PDA slant with $10 \mathrm{ml}$ PBS buffer and collected in a sterile tube prior to use (19). Fungal spores were counted using a hemocytometer under light microscope.

\section{Microscopic imagining of microalgae/fungi complex}

The pelletized microalgae/fungi biomass was picked up in order to perform a microscopic study and was photographed under the microscopes (Olympus) with objective lenses of 40 magnifications.

\section{Determination of microalgal growth}

Daily measurement of the inoculated medium algal culture of Optical density (OD) at $680 \mathrm{~nm}$ using a spectrophotometer as an indicator for algal growth density. A linear relationship between OD and dry weight $(D W, g / L)$ was determined for algal strain (20): Dry weight $(\mathrm{g} / \mathrm{l})=0.34 \mathrm{OD}_{680}-0.0068, \mathrm{R} 2=$ 0.997.

Calculate the harvesting ratio of microalga according to the following formula:

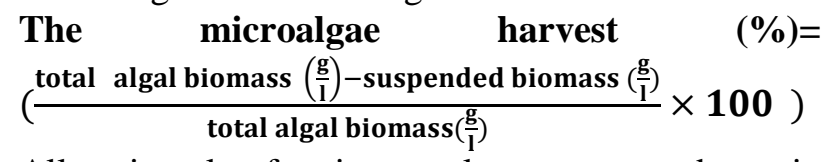

All microalga-fungi co-cultures were done in triplicate and mean value and standard error of results was calculated to assess the difference between samples. The concentration of glucose was strong-minded using the dinitrosalicylic acid examine (21).

\section{Results and Discussion: \\ Screening the capability of isolated fungal strains for formation of pellets}

The isolated fungal strains belong to filamentous fungi (as recorded in Table 1) revealed that some of isolated candidate fungal strains showed fungal mycelium on PDA plates after 5-days of cultivation. The isolated fungal strains were more examined for pellets-forming capability by growing fungal spores of these candidate fungal strains on PGB medium. It was found that only one fungal 
strain (A. niger) established pellet-forming ability (1-5 $\mathrm{mm}$ diameter) while other fungal strains formed loose ones, suggesting that pellet-formation for filamentous fungi is strain-specific. This was in agreement with other investigations (22). Filamentous fungi characterize suitable bioflocculating agents because of their selfpelletization and extraordinary microalgal trapping efficiencies. Fungal self-pelletization has been observed for numerous filamentous strains $(23,24)$. Aggregates/pellets were representatives of Aspergillus spp., Basidiomycete spp, Phanerochaete spp, (25).

Table 1. Pellets-forming of isolated filamentous fungal strains derived from municipal wastewater mud

\begin{tabular}{cccc}
\hline Fungi Isolates & $\begin{array}{c}\text { Pellet } \\
\text { formation } \\
\text { capability }\end{array}$ & $\begin{array}{c}\text { Early } \\
\mathbf{p H}\end{array}$ & $\begin{array}{c}\text { Last } \\
\mathbf{p H}\end{array}$ \\
\hline Aspergillus niger & + & 6.7 & 4.8 \\
A.flavous & - & 7 & 5.7 \\
Penicillum sp. & - & 6.8 & 5.6 \\
Alternaria $\boldsymbol{s p .}$ & - & 6.5 & 5.7 \\
\hline
\end{tabular}

Note: $+=$ pellets-forming and $-=$ non-pellets-forming

Fungal assisted bio-flocculation of heterotrophic microalgal cells

The filamentous fungus $A$. niger could assist bioflocculation of heterotrophic microalgal cells by formation of pellets under certain conditions (Fig. 1). The algae lost culture most of its green color, and turned transparent; microalgal cells were pelleted (15).

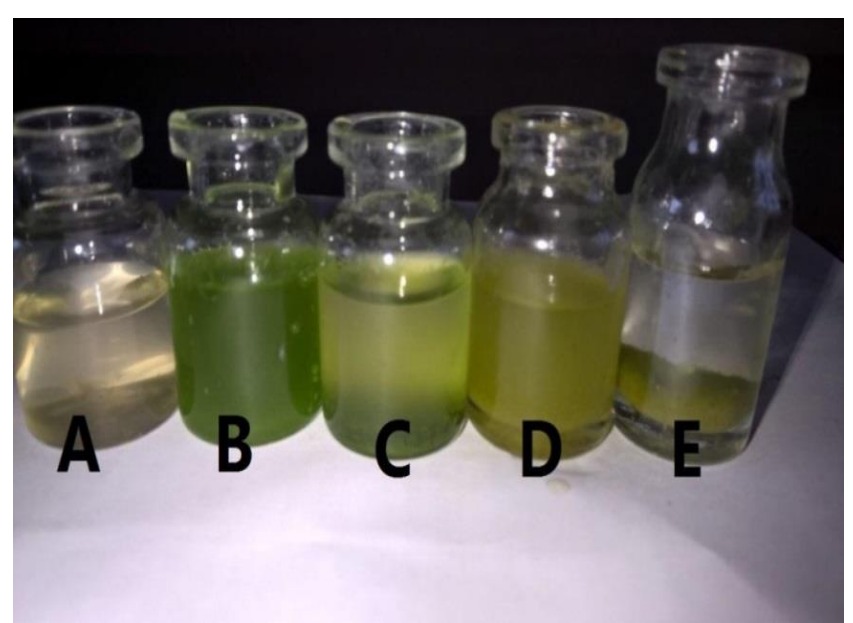

Figure 1. Flocculation of the microalgal Chlorella vulgaris by Aspergillus niger. (A) A. niger culture (B) C.vulgaris autotrophically grown culture (C) Flocculation of C.vulgaris autotrophically grown co-cultured with A. niger (D) C.vulgaris Mixotrophically grown (E) Flocculation of C.vulgaris heterotrophic culture mixed with $A$. niger pellets, time $24 \mathrm{~h}$ later.
Spores inocula of different concentrations were added to culture media ranged from $1 \times 10^{2}$ to $1 \times 10^{5}$ spores/mL could help the formation of fungi-algae pellets under heterotrophic growth conditions (Table 2). It was found that when initial spores inoculums was $1 \times 10^{6}$ spores $/ \mathrm{mL}$, fungi-algae pellets was not observed even after 7 days of cultivation., which is in agreement with reports by Foster (26), who explained that fungal cell pelletization ,number and size of pellets depending on the inoculum concentration of fungal spores(27, 28) Meanwhil,e the early spore concentration of $1 \times 10^{4}$ spores/ ml was suitable for well-organized pellets formation in short growth period.This inoculum size was used in the following experiments.

Table 2. Effect of inoculum size on the fungialgae pellet formation

\begin{tabular}{cccccc}
\hline \multirow{2}{*}{ Parameters } & \multicolumn{5}{c}{ Inoculums size (spores/ml) } \\
\cline { 2 - 6 } & $1 \times 10^{2}$ & $1 \times 10^{3}$ & $1 \times 10^{4}$ & $1 \times 10^{5}$ & $1 \times 10^{6}$ \\
\hline High pH & 7.01 & 7.04 & 7.04 & 6.94 & 7.11 \\
$\begin{array}{c}\text { Low pH } \\
\text { Culture time } \\
(\text { day) }\end{array}$ & 5.02 & 4.9 & 4.5 & 4.02 & 4.05 \\
$\begin{array}{c}\text { Pellet } \\
\text { formation }\end{array}$ & 4 & 4 & 4 & 4 & 5 \\
\hline
\end{tabular}

Note: + stands for pellets-forming; - stands for non-pelletsforming.

Results show that $\mathrm{pH}$ was the major factor that effected on the formation of the algae-fungal pellets.It was suggested that the algae have negative surface charge. The reason for this is the occurrence of proton-active carboxylic, phosphoric, hydroxyl and amine functional groups (29). Fungal hyphae and mycelia are positively charged because they contain polysaccharides. This can possibly neutralize the negative charges on the algal surface, allowing the attachment to the fungal cell wall. Moreover, fungi secret hydrolytic enzymes in the presence of the microalgal cells, the surface charge and the cell size and density were the main factors for the stability of microalgae suspension in the culture (30). Filamentous fungi $A$. niger cells with microalga cells $C$. vulgaris cells (co-cultured) formed cell pellets. These pellets were sphere-shaped, relatively homogeneous in size and dense the pellets in the co-culture showed green color instead of grey one (Fig. 2). The observed green color of pellets was formed due to microalgal cells entrapped in or attached to the hyphae of the filamentous fungus $A$. niger, and the size of the pellets was about 3-6 mm (Fig. 3) This technique can provide an easy way to harvest microalgae cells through filtration with a sieve. $(31,32)$. 

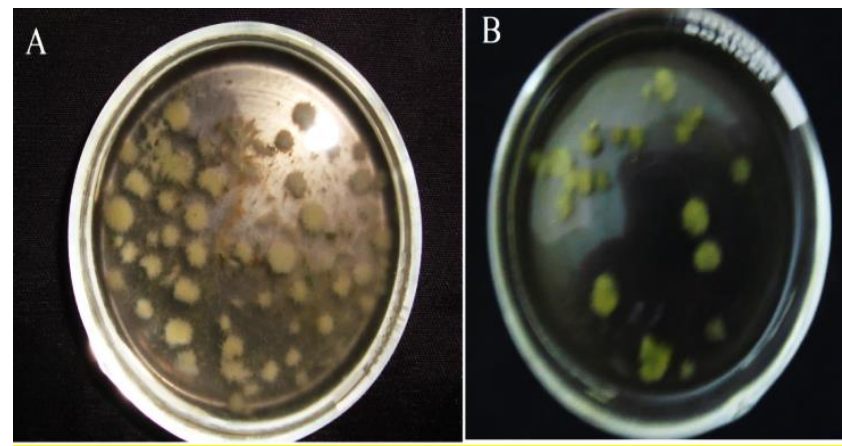

Figure 2. Comparison of fungi pellets/fungialgae pellets grown on shaker under different rotation speed: (A: heterotrophic algae and B: autotrophic algae) fungi and fungi-pellets formation with rotation speed at $150 \mathrm{rpm} / \mathrm{min}$. after $72 \mathrm{~h}$ of incubation.

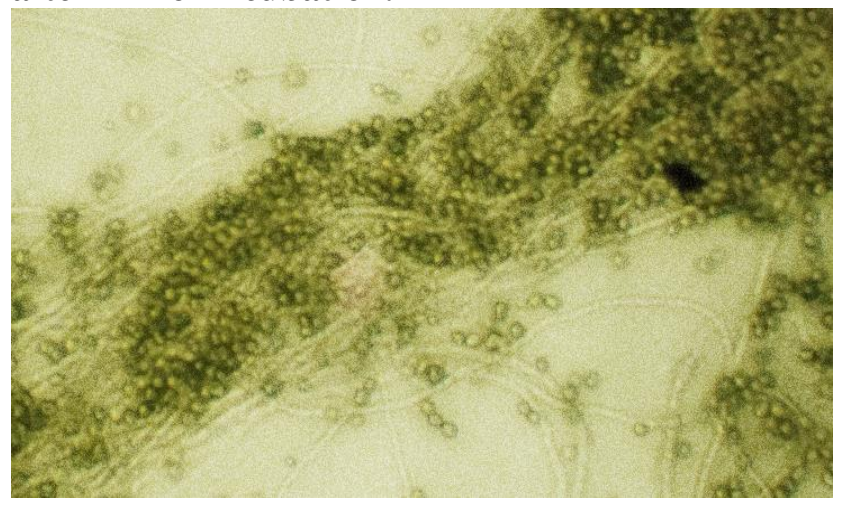

Figure 3. Microscopic photo of fungus-algae complex biomass visualized under Olympus-BH2 with 40 magnifications.

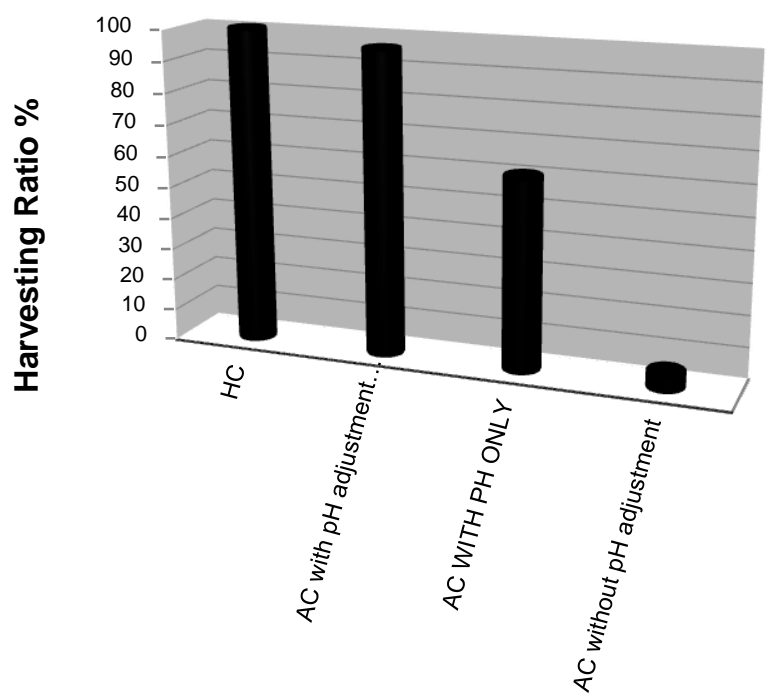

Figure 4. harvesting ratio by filamentous fungus isolate Aspergillus niger under numerous cultivation conditions. AC: autotrophic algal culture; HC: heterotrophic algal culture.

Microalgae harvesting ratio by filamentous fungus under heterotrophic conditions was shown to be better than autotrophic condition for the formation of pellets (Fig. 4). In heterotrophic condition, the competition occurred between cells of A. niger and cells of $C$. vulgaris for the glucose in the co-cultureis because both cells need an organic carbon source to maintain their life (33). In mixotrophic conditions, competing for nutrients with heterotrophic algal cells, while a symbiotic relationship formation between fungi and autotrophic microalgal cells, also it seemed that the concentration of fungal biomass in the co-culture was moderately higher at glucose than sucrose, maltose source of carbon. Glucose consumption rate by the fungus is much faster than that by the microalgal when the amount of glucose was abundant. This may be due to the high efficient metabolic ability of fungi (34). Under autotrophic cultures, phototrophic cultivations after 3 days, no pellets were formed in the co-culture. the growth of microalga was very slow and the fungal spores were not germinated. It was apparent that co-pelletization relies on the existence of an organic carbon (35). Experiments with different carbon source of glucose, sucrose, maltose showed that the higher harvest efficiency of microalgae was more in glucose source than sucrose and maltose. The size of the pellets formed in the co-culture is larger, and the total number of the pellets increases on glucose which provided a sufficient carbon source to sustain the cell growth, especially the fungal cells, which therefore resulted in better pelletization and harvest efficiently (31).

\section{References:}

1. Teresa MM, Antonio AM, Nidia CS. Microalgae for biodiesel production and other applications. Renew. Sust. Energ. Rev, 2010; 14(1): 217-32.

2. Al-rubaiee GH, and Jawad AM, Starvation of Green algae Scenedesmus quadricauda to stimulate the production of total lipid and total protein. Iraqi Journal of Biotechnology, 2015; 4(2): 197-206.

3. Huang G, Chen F, Wei D, Zhang X, Chen G. Biodiesel production by microalgal biotechnology. Appl. Energy, 2010; 87(1): 38-46.

4. Sina S, Rouke B, Marian HV, René H WHarvesting of microalgae by bio-flocculation. J Appl Phycol. 2011; 23(5): 849-855.

5. Rettenmaier AC. Methods of Algae Harvesting Utilizing a Filtering Substances and Uses Therefore. US Patent, Patent No. US. 2013; 518(8):132-142.

6. Nazim M, Mohamed T, F M Digby, W, Krishna K, Amit G, Trevor S, Andrew S and Aidyn M. Fungalassisted algal flocculation: application in wastewater treatment and biofuel production. Biotechnology for Biofuels, 2015; 8 (1): p1-23.

7. Sarman OG, and Bo HuReview of Microalgae Harvesting via Co-Pelletization with Filamentous Fungus. Energies. 2013 6(11): 5921-5939.

8. Jigar HS, Abhijeet D, Kushal P, Keyur P, Alpesh V. A Comprehensive Overview on Various Method of Harvesting Microalgae According to Indian Perspective. International Conference on 
Multidisciplinary Research and Practice. 2015; 1 (4):113-117.

9. Theoneste N, Xianhai Z, Theophile M, Emmanuel M, Ning H, Wenyao S. and Yinghua LHarvesting of freshwater microalgae with microbial bioflocculant: a pilot-scale study. Biotechnol Biofuels. 2016; 27(9):35-47.

10. Ndikubwimana T, Zeng X, Liu Y, Chang JS, Lu Y. Harvesting of microalgae Desmodesmus sp. F51 by bioflocculation with bacterial bioflocculant. Algal Res.2014; 6:186-93.

11. Salim S, Kosterink N, Wacka NT, Vermuë M, Wijffels R. Mechanism behind autoflocculation of unicellular green microalgae Ettlia texensis. J Biotechnol. 2014; 174:34-8.

12. Zhang J, Hu B. A novel method to harvest microalgae via co-culture of filamentous fungi to form cell pellets. Bioresour Technol. 2012; 114:529-35.

13. Xie S, Sun S, Dai SY, Yuan JS. Efficient coagulation of microalgae in cultures with filamentous fungi. Algal Res. 2013; 2(1):28-33. Aug. 27, 2013.

14. Bala Subramanian S, Yan, S, Tyagi, R D, Surampalli RY. Isolation of Extra Cellular Biopolymer Producing Microorganisms from Wastewater Sludge for Sludge Settling and Dewatering Proceedings of Water Environment Federation (WEFTEC-06), 79th Annual Technical Exhibition and Conference, October 21-25, Dallas Convention Center, Dallas, Texas, USA 2006; pp-473-489.

15. Barnett HL, Hunter BB. Illustrated genera of imperfect fungi. Burgess Pub. Co., Minneapolis, Minnesota, USA. Barnett H.L. Illustrated Genera of Imperfect Fungi. 2 nd. Ed. Burgess publishing company; 1972. 228p.

16. Stein, JR. Handbook of Phycological Methods: Culture Methods and Growth measurements. Phyco.Soc.of Am.Inc.; 1973. p 788-792.

17. Zhou wM, Min B Hu, X Ma, Y Cheng, Y Liu, P Chen, R Ruan. A hetero-photoautotrophic two-stage cultivation process to improve wastewater nutrient removal and enhance algal lipid accumulation, Bioresour. Technol., 2012; 110: 448-455.

18. Alam, M, Fakhru'l R. Enhanced settle ability and dewater ability of fungal treated domestic wastewater sludge by liquid state bioconversion process, Water Res., 2003; 37 (5)1118-1124.

19. Wang Y, Li P, Chen M Min Y, Chen J, Zhu R, Ruan. Anaerobic digested dairy manure as a nutrient supplement for cultivation of oil-rich green microalgae Chlorella sp, Bioresour. Technol. 2010; 101(8):2623-2628.

20. Miller GL. Use of dinitrosalicylic acid reagent for determination of reducing sugar, Anal. Chem. 31. 1959; p: 426-432.

21. Fujita MK, Iwahori K, Yamakawa. Pellet formation of fungi and its application to starch wastewater treatment, Water Sci. Technol.,1993; 28 (2): $267-$ 274.

22. More TT S, Yan RD, Tyagi RY. Surampalli, Potential use of ilamentous fungi wastewater sludge treatment, Bioresour. Technol., 2010; 101 (20): 7691-7700.

23. Zhang JG, Hu B. A novel method to harvest microalgae via co-culture of filamentous fungi to form cell pellets. Bioresource Technology. 2012; 114:529-535.

24. Luo SS, Dong ZJ, Wu XD, Liu YH, Ruan R. Pelletization Behavior of Fungal Chlorella sp. Symbiosis System. Research J. of Biotechnology. 2013; 8(1):56-59.

25. Xia CJ, Wei W, Hu B (2014) Statistical Analysis and Modeling of Pelletized Cultivation of Mucor circinelloides for Microbial Lipid Accumulation. Applied Biochemistry and Biotechnology 172:35023512.

26. Liu Y, Liao W, Chen SL .Study of pellet formation of filamentous fungi Rhizopus oryzae using a multiple logistic regression model. Biotechnology and Bioengineering. 2008; 99(1):117-128.

27. Foster JW, Chemical Activities of Fungi, Academic Press, New York, 1949.

28. Metz B, Kossen WF, The growth of molds in the form of pellets - a literature review, Biotechnol. Bioeng., 1977; 19 (6): 781-799.

29. Metz B, Kossen, NW. The growth of molds in the form of pellets-A literature review. Biotechnol. Bioeng., 1977; 19(1):781-799.

30. Zmak PM, Podgornik, A, Podgornik H, Koloini T. Impact of pellet size on growth and lignin peroxidase activity of Phanerochaete chrysosporium. World J. Microbial. Biotechnol, 2006; 22(12):1243-1249.

31. Muradov N, Mohamed T, Ana F M, Digby W, Krishna K, Amit G, Trevor S, Andrew S Ball and Aidyn $M$ Fungal-assisted algal flocculation: application in wastewater treatment and biofuel production.2015; 8(2):320-329.

32. Muradov N, Fidalgo B, Gujar AC, T-Raissi A. Pyrolysis of fast-growing aquatic biomass - Lemna minor (duckweed): characterization of pyrolysis products. Bioresour Technol. 2010; 101(21):842484248 .

33. Hadjoudja S, Deluchat V, Baudu, M. Cell surface characterization of Microcystis aeruginosa and Chlorella vulgaris. J. Colloid Interface Sci., 2010;34(2): 293-299.

34. Sarman O G and Bo Hu). Review of Microalgae Harvesting via Co-Pelletization with Filamentous Fungus. Energies .2013; 6(1):5921-5939

35. Sarman O, ktovianus G, Carlos Z, and Bo $\mathrm{H}$. Microalgae Harvest through Fungal Pelletization CoCulture of Chlorella vulgaris and Aspergillus niger. Energies. 2014;7(7):4417-4429. 


\section{حصاد الطحلب الدقيق كلوريلا فولجارس عند طريق التلبد المشترك مع الفطريات الخيطية}

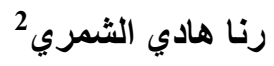

غيداء حسين الربيعي 1

1، 2 قسم علوم الحياة، كلية العلوم ، الجامعة المستتصرية، بغداد،العراق.

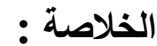

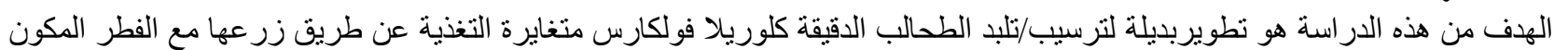

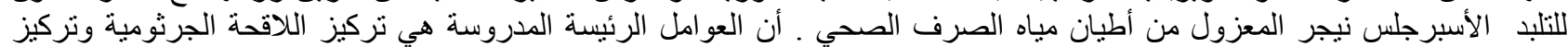

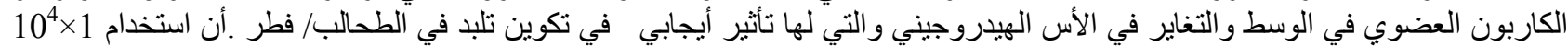

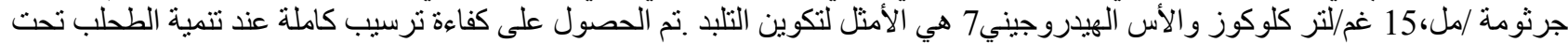

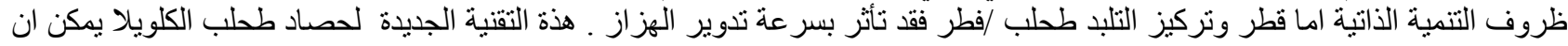

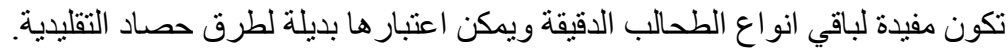

الكلمات المفتاحية: الترسيب البايولوجي، طحالب متغايرة التغذية، طحالب ذاتية التغذية، فطريات خيطية . 